\title{
LOS CIEN AÑOS DEL HOSPITAL Víctor LARCo HERRERA
}

\author{
The one hundred years of the Hospital Victor Larco \\ Herrera
}

\section{Santiago Stucchi-Portocarrero ${ }^{1}$}

\begin{abstract}
Resumen
El actual Hospital Víctor Larco Herrera fue inaugurado el 1 de enero de 1918, como Asilo Colonia de la Magdalena, en un contexto de transición entre el alienismo del siglo XIX y una psiquiatría que reclamaba su lugar entre las especialidades médicas, a la vez que el liderazgo en la conducción de los hospitales, como representante de la ciencia positiva. La fundación del nuevo establecimiento fue considerada "la segunda revolución psiquiátrica" en el Perú, y generó muchas expectativas, inspirándose en la terapia por el trabajo y en los principios de no restricción y puertas abiertas.
\end{abstract}

Palabras clave: Hospital Victor Larco Herrera, asilo colonia, manicomio, hospital, psiquiatría.

\begin{abstract}
The current Víctor Larco Herrera Hospital was inaugurated on January 1 of 1918, as Asilo Colonia de la Magdalena, in a context of transition between alienism of the nineteenth-century and a psychiatry that claimed its place among medical specialties, and leadership in the hospital management as a representative of positivism. The foundation of the new hospital was considered "the second psychiatric revolution" in Peru; and, it generated many expectations and it was inspired by work therapy and nonrestraint and open-door principles.
\end{abstract}

Key words: Victor Larco Herrera Hospital, colony asylum, asylum, hospital, psychiatry.

\footnotetext{
"La insanidad, "fruto directo de la civilización", es una enfermedad curable; y, el adelanto de un pueblo; su grado de cultura, (...) está en razón directa de la atención y cuidado que presta á los insanos, mejorando sus manicomios, lugares de horror para el vulgo, de criminal curiosidad á veces, y en donde el más infortunado de los desheredados, encuentra no sólo defensa contra los peligros que le rodean, sino también las mayores probabilidades para su curación (...) Los hospitales para locos son, en estos casos, un consuelo y una esperanza".
}

Manuel Antonio Muñiz (1) $\mathfrak{t}$ 1 de enero de 1918 abrió sus puertas el Asilo Colonia de la Magdalena, denominado Asilo Colonia Víctor Larco Herrera en 1921 (2), y Hospital Víctor Larco Herrera a partir de 1930 (3), en homenaje a su mayor benefactor. Su fundación fue considerada como el inicio de "la segunda revolución psiquiátrica" en el Perú (4), generando grandes expectativas, en un contexto de transición entre el alienismo decimonónico y el nacimiento de la psiquiatría como especialidad médica en nuestro país.

El Asilo Colonia recibió a los internos del Hospital Civil de la Misericordia (o Manicomio del Cercado), que había sido inaugurado en 1859, bajo la inspiración tardía del tratamiento moral proveniente de Europa. (5) El primer manicomio del Perú había quedado obsoleto, los ambientes estrechos no permitían separar "los enajenados curables de los incurables, los indigentes de los pensionistas, los sucios de los aseados, los furiosos de los tranquilos, los ociosos de los trabajadores, los atacados de enfermedades contagiosas ó no de los sanos". (6) Asimismo, la insistencia en la necesidad de internamiento para todos los enfermos mentales, bajo la premisa del asilo curativo, había llevado también al colapso de lo que fue "la primera revolución psiquiátrica en el Perú". (4)

\footnotetext{
1 Médico psiquiatra. Instituto Nacional de Salud Mental Honorio Delgado-Hideyo Noguchi, Universidad Peruana Cayetano Heredia, Lima.
} 
Cuando en 1896, el gobierno peruano convocó a un concurso buscando el mejor proyecto de construcción para una nueva casa de insanos, había comenzado a afianzarse en nuestro medio la palabra "psiquiatría", acuñada casi un siglo antes, en 1808, por Johann Christian Reil) (7), en detrimento del término "alienismo". No se trataba solo de un cambio de nombre: el alienismo se identificó preferentemente con el cuidado intramanicomial y con la locura como eje de su intervención, en tanto que la psiquiatría reivindicó para sí el campo de las patologías mentales que no implicaban la pérdida de la razón, incursionando más allá de los reducidos muros del asilo -según Michel Foucault-, el alienismo se centró en el delirio como antagonista de la verdad en tanto que la psiquiatría se desarrollará en base a la oposición entre lo involuntario y lo voluntario). (8) Esta modificación semántica no fue inmediata y durante un tiempo ambos vocablos se utilizaron indistintamente. Por poner algunos ejemplos, la palabra "psiquiatría" se encuentra ausente en el artículo de Manuel Antonio Muñiz sobre el Manicomio de Lima, de 18851886 (6), aunque menciona en su lugar a la "frenopatía". Más adelante, en el proyecto del mismo Muñiz, ganador del concurso de 1896 (1), así como en un artículo de Baltazar Caravedo de 1915 (9), figuran "psiquiatría" y "psiquiatras" a la par que "alienistas". Y, en una publicación de 1918, Honorio Delgado y Carlos Bambarén no hacen más referencia al alienismo sino únicamente a la psiquiatría. (10)

De todos modos, a principios del siglo $X X$ la psiquiatría reclamaba su sitio entre las demás especialidades médicas, y en tal sentido el psiquiatra debía contar con un espacio propicio para aplicar sus tratamientos. Muñiz ya había dejado en claro que los hospitales debían "disponer de los adelantos terapéuticos en Hidroterapia y Electricidad". (1) Inclusive, el tratamiento moral, en franco declive en Europa desde mediados del siglo XIX, encontró su lugar junto a la visión organicista de la enfermedad mental que predominó desde finales del siglo XIX (en el fundamento para un proyecto de ley sobre asistencia psiquiátrica de 1928, puede leerse que "la alienación mental es una enfermedad del cerebro", coincidiendo con el famoso enunciado de Wilhelm Griesinger). (11) Así, un artículo publicado en "La Reforma Médica", en 1915, saludó que el Asilo Colonia, próximo a inaugurarse, permitiera aplicar "el tratamiento moral" (12), aunque es probable que a esas alturas aquél se encontrase reducido conceptualmente a "buen trato" o "distracción de la locura". (13)

Del mismo modo, para Muñiz la distribución de los internos en pabellones según su condición clínica constituyó “La primera y más importante cuestión (...), la más grave por sus irremediables consecuencias en caso de error", proponiendo en su proyecto las siguientes secciones: "1. ${ }^{\circ}$ Para pensionistas de diversas categorías. 2. ${ }^{\circ}$ Para enfermos de observación y de vigilancia continua, como locos recientes, suicidas, impulsivos, criminales, destructores, sitiófobos, etc. $3 .^{\circ}$ Para agitados, ruidosos, etc. 4. ${ }^{\circ}$ Para sucios, idiotas, dementes, epilépticos sucios, etc. $5 .^{\circ}$ Para tranquilos y convalecientes, maniacos sin delirio, estáticos, alucinados, etc.; y 6. Para crónicos, seniles, incurables, etc." . (1)

El trabajo ocupó un puesto fundamental en la terapia. Philippe Pinel había mencionado, a fines del siglo XVIII, que "La ley básica de cualquier hospital de locos es el trabajo mecánico" ya que la actividad física en general constituía el mejor remedio contra la ociosidad del insano y "el encadenamiento vicioso de sus ideas"; en forma particular, las faenas agrícolas aprovechaban "el instinto natural del hombre a fecundar la tierra, para satisfacer sus necesidades con los frutos de su industria". (14) Casi un siglo después, Jules Falret opinó 
a favor de "crear colonias agrícolas anexas a grandes manicomios". (15) En opinión de Muñiz, "el alienado debe trabajar" y las labores podían ser múltiples: "porteros, jardineros, (...) albañiles, carpinteros, pintores"; las mujeres debían dedicarse preferentemente a "lavandería, costura y trabajo de mano" mientras que los varones a "ser cigarreros, sombrereros, sastres, zapateros, escoberos, (...) fabricantes de esteras, de cepillos, de asientos de paja, (...) colchoneros, herreros, etc.". (1) Para Caravedo, "La inactividad conduce a la demencia". (16)

A fines del siglo XIX, el trabajo en los asilos se orientó preferentemente hacia la producción industrial -aunque fuese a pequeña escala- $\mathrm{y}$ la autosuficiencia económica, acorde con un sistema capitalista en ascenso "que valoraba a las personas por su inserción en el proceso productivo". (17) En palabras de Caravedo: "El trabajo no sólo es agente terapéutico de primera importancia, que acelera la curación, sino también, fuente inagotable de recursos, que contribuye en parte al sostenimiento de los Hospitales Psiquiátricos". (16) Por otro lado, la idea del trabajo terapéutico se amoldó perfectamente a los novedosos principios de no restricción y puertas abiertas que se popularizaron como respuesta al encierro asilar preconizado por el alienismo (José Casimiro Ulloa había advertido que el loco "puede herir, matar a los que se presenten en su camino: puede saquear, destruir, incendiar la propiedad de otros", y por lo tanto "debe ser privado de su libertad", en tanto que para Muñiz, el "aislamiento ó secuestración, en los asilos ó no, es sin duda el más competente factor de curabilidad"). (1,18) La sobrepoblación asilar resultante, sumada a una visión pesimista de la enfermedad mental propiciada por la teoría degeneracionista habían llevado a un desprestigio de la reclusión manicomial, la que a fines del siglo XIX solo sobrevivía como una "necesidad social" ante la amenaza del "loco peligroso". (19).

En este contexto, algunas de las alternativas planteadas fueron la villa asilar, la colonia agrícola y el asilo colonia, amalgamas de una semilibertad con disciplina laboral y las bondades de la vida rural bajo la inspiración primigenia de la legendaria comunidad de Gheel ("el pueblo de los locos"), en Bélgica, y las posteriores experiencias de Alt-Scherbitz, en Alemania; Fitz-James, en Francia, y Bangour Village Asylum, en Escocia, entre otras (20). En América son dignas de mención las Colonias de Ilha do Governador y la Colonia de Jacarepaguá (futura Colonia Juliano Moreira), fundadas en 1890 y 1924, respectivamente, en Brasil (21); la Colonia Open-Door de Luján y la Quinta de Lomas, abiertas en 1897 y 1908 respectivamente, en Argentina (22), y la Colonia Open-Door (luego Hospital Psiquiátrico El Peral), creado en 1928 en Chile. (23) Para Muñiz, en el Perú de aquel entonces no eran viables "ni la creación de asilos privados, ni la asistencia en familias, ni siquiera las colonias agrícolas", inclinándose a favor de un asilo colonia, cuya "construcción debe obedecer al open-door y no-restraint, debiendo ser apropiado para la organización del trabajo manual y para la colonización agrícola"; de alguna forma, se trataba de "dejar al enajenado la ilusión de la libertad, sin que nada le recuerde su condición de recluido". (1).

Pocos años antes de su inauguración oficial, el Asilo Colonia había comenzado a recibir algunos pacientes. "Hemos visto con frecuencia -relataba Caravedo en 1915- durante los ocho meses que trabajan los alienados en el Asilo de la Magdalena, que sujetos inertes, al parecer verdaderos dementes, unos, y exitados [sic] y peligrosos otros, cambiar sus fisonomías clínicas, al poco tiempo de estar sometidos, única y exclusivamente á este tratamiento, que 
no sólo es un recurso para mejorar el estado físico de ciertos enfermos, estimulando y regularizando las funciones orgánicas sino también un agente moral poderoso". (9).

El Comercio informó, el 2 de enero de 1918, que los inquilinos del nuevo hospicio "recibirán los beneficios del campo, de locales amplios y cómodos, construídos á todo costo y preparados para implantarse en ellos, los sistemas modernos que la ciencia aconseja, para el tratamiento de los alienados". (24) En un artículo aparecido en la revista Mundial en 1920, el autor proclamó que "ya no hay locos en el asilo colonia", en tanto que uno de los internos entrevistados dijo: " ¿Yo? No soy enfermo, soy empleado. Los enfermos se quedaron allá en la otra casa donde daban 'baños de chaqueta' y encerraban en la 'jaula'. Aquí todos somos empleados". (25) Sin embargo, el nuevo local sería a la vez "hospital, hospicio y colonia". (12).

Para los autores del proyecto de ley de 1928, antes citado, la asistencia psiquiátrica debía dirigirse no solo a los alienados crónicos, en los hospicios y asilos, sino también a los alienados agudos y a los psicópatas (entendiendo este término como "enfermos mentales no alienados"), y para estos el establecimiento idóneo debía ser el hospital psiquiátrico. De este modo, los mismos autores propusieron "con carácter de urgencia, la transformación del Asilo Colonia de Magdalena en Hospital Psiquiátrico". (11) Dos años después, en diciembre de 1930, el cambio de denominación se hizo efectivo. (3).

La pujante psiquiatría demandaba además el liderazgo en la conducción del hospital, en consonancia con la creciente autoridad de la clase médica a la que reclamaba pertenecer. Dicha autoridad se había ido consolidando en el Perú a lo largo del siglo XIX como emblema de un poder basado en el conocimiento -en la ciencia positiva- $(26,27)$, llevando a Ulloa a incluir, entre "las sagradas funciones del médico", la "protección misma de los enfermos y del orden social". (28) Por tal motivo, Muñiz aseveró en su proyecto que "no se concibe Manicomio medianamente organizado en el que el médico no sea el Director y el árbitro del funcionamiento de todo su mecanismo". (1) Y, así también, en el artículo de La Reforma Médica, citado antes, los autores criticaron que en la propuesta de reglamento para el Asilo de la Magdalena no figurase el cargo de director médico, recordando que "los asilos son además de lugares de asistencia centros de cultura". (12).

Pero el mayor obstáculo que encontró el gremio psiquiátrico para sus anhelos de control y reforma fueron las Hermanas de la Caridad, percibidas como sobrevivientes de una rancia tradición de raíces virreinales, símbolo de atraso y de "una concepción demonológica y perversa del desorden mental". (29) Por añadidura, los médicos contaban con el respaldo del acaudalado hacendado Víctor Larco Herrera, miembro de "la burguesía agraria pingüe y en ascenso al poder" (29), quien fue nombrado inspector en 1919. Las religiosas fueron culpadas -probablemente no sin razón- de malos manejos económicos, de falta de higiene $\mathrm{y}$, sobre todo, de tratos crueles con los internos (mayores detalles pueden leerse en la biografía de Larco Herrera, escrita por Valdizán) (30), retirándose del Asilo Colonia en 1919 para ser reemplazadas por enfermeras de la Escuela Mixta de la Sociedad de Beneficencia. Finalmente, en 1921 se nombró a Hermilio Valdizán como director médico del hospital. Podemos afirmar que con estos hechos comenzó formalmente la psiquiatría en el Perú. (31). 
Los años siguientes conocerán tiempos de esplendor, asociados a la formación docente, la investigación y la aplicación de modalidades terapéuticas de vanguardia para la época. (31) Pero, tempranamente también, el Hospital Víctor Larco Herrera repetirá la historia de su predecesor, sumiéndose progresivamente en el hacinamiento y el abandono, lo ha sido relatado en varias publicaciones. (32-34) Un destino similar al de hospitales psiquiátricos de otros países, como por ejemplo el Hospicio de las Mercedes (actual Hospital Municipal José Tiburcio Borda), en Argentina (22); el Manicomio Nacional Pacheco (actual Instituto Nacional de Psiquiatría Gregorio Pacheco), en Bolivia (35), y el Manicomio General La Castañeda, en México (17).

Durante los últimos años se ha dado en el Perú una serie de medidas legales y administrativas que buscan fomentar la prestación de servicios de salud mental en los niveles de atención primario y secundario a la vez que la reintegración precoz del paciente mental a la comunidad, dejando el internamiento como una opción última, discurso diametralmente opuesto al del alienismo del siglo XIX. Esta política, de imperiosa necesidad para los tiempos actuales, ha sido considerada como una reforma (36), ¿podríamos decir, la tercera en el Perú? Bajo tal óptica, la imagen del hospital psiquiátrico deviene en anacrónica y hay quienes piden su pronto final, comenzando probablemente por el establecimiento cuasi centenario. No obstante, cabe preguntarse si no exige prudencia semejante medida y si no tendría razón Ervin Goffman hace más de medio siglo, cuando vaticinaba, refiriéndose al cierre de los hospitales psiquiátricos, que "mañana los parientes, la policía y los jueces clamarían pidiendo otros". (37) El debate está abierto.

\section{REFERENCIAS BibLIOGRÁFICAS}

1. Muñiz MA. Asistencia pública de los enajenados. Concurso para la construcción de un manicomio. Texto. Lima: Ministerio de Fomento; 1897.

2. Boletín de la Sociedad de Beneficencia Pública: 1921; 16 (371): 8.

3. Boletín de la Sociedad de Beneficencia Pública: 1930; 25 (490): 1.

4. Valdivia Ponce O. Historia de la psiquiatría peruana. Lima: Gráfica Morsom SA; 1964.

5. Stucchi Portocarrero S. El tratamiento moral y los inicios del manicomio en el Perú. Revista de Neuro-Psiquiatría. 2015; 78 (3): 151-156.

6. Muñiz MA. El manicomio de Lima 1884. La Crónica Médica. 1885; 2 (13): 7-8, (14): 52-56, (15): 93-95. 1886; 3 (28): 143-144.

7. Marneros A. Psychiatry's 200th birthday. The British Journal of Psychiatry. 2008; 193 (1): 1-3.

8. Foucault M. Los anormales. Curso en el Collège de France (1974-1975). México: Fondo de Cultura Económica; 2001.

9. Caravedo B. La asistencia de los alienados en el Perú. La Reforma Médica. 1915; 1 (4): 5-7.

10. Delgado H, Bambarén CA. Algo sobre etiología y profilaxia de la locura a propósito del movimiento estadístico del "Hospicio de Insanos de Lima". Anales de la Facultad de Medicina. 1918; 1: 78-111.

11. Cornejo AG, Lorente S, Caravedo B. Legislación sobre asistencia de los alienados y de los toxicómanos. Lima: Imprenta Americana; 1928.

12. Anónimo. Organización del Asilo Colonia de la Magdalena. La Reforma Médica. 1915; 1 (1): 4-5.

13. Morel P, Quétel C. Las terapéuticas de la alienación mental en el siglo XIX. En: Postel J, Quétel C (ed). Nueva historia de la psiquiatría. México: Fondo de Cultura Económica; 2000. p. 299-310.

14. Pinel P. Traité médico-philosophique sur l'aliénation mentale, ou la manie. Paris: Richard, Caille et Ravier; 1799.

15. Falret J. Les aliénés et les asiles d'aliénés. Paris: Librairie J.-B. Bailliére et fils; 1890.

16. Caravedo B. Memoria de la Dirección. Correspondiente al primer trimestre de 1932. Lima: Imprenta Hospital "Víctor Larco Herrera"; 1932.

17. Sacristán C. Por el bien de la economía nacional. 
Trabajo terapéutico y asistencia pública en el Manicomio de La Castañeda de la ciudad de México, 1929-1932. História, Ciências, Saúde Manguinhos. 2005; 12 (3): 675-692.

18. Ulloa JC. De la reclusión de los enajenados. $\mathrm{La}$ Gaceta Médica. 1861; 121: 321.

19. Scull A. La locura: Una breve introducción. Madrid: Alianza Editorial; 2013.

20. Allmond, G. Liberty and the individual: the colony asylum in Scotland and England. History of Psychiatry. 2017; 28 (1): 29-43.

21. Venancio ATA. Da colônia agrícola ao hospitalcolônia: configurações para a assistência psiquiátrica no Brasil na primeira metade do século XX. História, Ciências, Saúde - Manguinhos. 2011; 18 (suppl 1); 35-52.

22. Requiere $M$. Beneficencia y asistencia social: la política manicomial en Buenos Aires. (1880-1940). Alcmeón. Revista Argentina de Clínica Neuropsiquiátrica. 2000; 9 (2): 169-194.

23. Gómez Chamorro M. La reconversión del Hospital Psiquiátrico El Peral en Red Comunitaria de Salud Mental y Psiquiatría. Cuadernos Médico Sociales (Chile). 2005; 45: 285-299.

24. Anónimo. El nuevo Manicomio. Importante comunicación del Inspector señor Elguera. El Comercio. Lima, 2 de enero de 1918. p. 1.

25. De Zavaleta, J. La alegre aldea de las almas ausentes. Mundial. 1920; 1 (29): 218-219.

26. Zárate Cárdenas E. La construcción del poder médico en el siglo XIX. Situa - Revista Semestral de la Facultad de Medicina Humana - UNSAAC. 2003; 11 (21): 9-15.

27. Amaya Núñez E. Manuel Antonio Muñiz y el proyecto de construcción del Manicomio General. Pendiente de publicación.

28. Ulloa JC. Anexos de la Memoria de la Beneficencia de Lima. Año de 1887.
29. Mariátegui J. Hermilio Valdizán y la psiquiatría peruana. Revista de Neuro-Psiquiatría. 1980; 43 (1): $1-22$.

30. Valdizán H. Víctor Larco Herrera: El hombre - La obra. Santiago: Imprenta Nascimento; 1934.

31. Mariátegui J. La psiquiatría peruana: presente y futuro. Revista de Neuro-Psiquiatría. 1999; 62 (1): 3-13.

32. Tarazona B. El Larco Herrera: ¿hospital o asilo? En: Portocarrero F, Sanborn C. De la caridad a la solidaridad: filantropía y voluntariado en el Perú. Lima: Universidad del Pacífico: 2003. p. 4772.

33. Stucchi Portocarrero, S. Loquerías, manicomios y hospitales psiquiátricos de Lima. Lima: Universidad Peruana Cayetano Heredia; 2012.

34. Prieto Sánchez, R. Guía demente. Soñadores y manicomios en la historia de Lima. Lima: Universidad Ricardo Palma; 2017.

35. Montellano Aparicio, H. Historia del Instituto Nacional de Psiquiatría Gregorio Pacheco. Revista Institucional Médica "Sucre". 2002; 67 (120121): 132-135.

36. Toyama M, Castillo H, Galea JT, Brandt LR, Mendoza M, Herrera V, et al. Peruvian mental health reform: a framework for scaling-up mental health services. International Journal of Health Policy and Management. 2017; 6 (9): 501-508.

37. Goffman E. Internados. Ensayos sobre la situación social de los enfermos mentales. Buenos Aires: Amorrortu editores; 2001.

38. Beneficencia Pública de Lima. Asilo Colonia de Magdalena. Lima: Casa Editora M. Moral; 1920.

39. Sociedad de Beneficencia Pública de Lima. Memoria correspondiente al año de 1920. Lima: Casa Editora M. Moral; 1920.

40. Anónimo. Variedades. 1918; 14 (514): 19.

\section{CORRESPONDENCIA:}

santiago.stucchi.p@upch.pe 


\section{FIGURAS:}

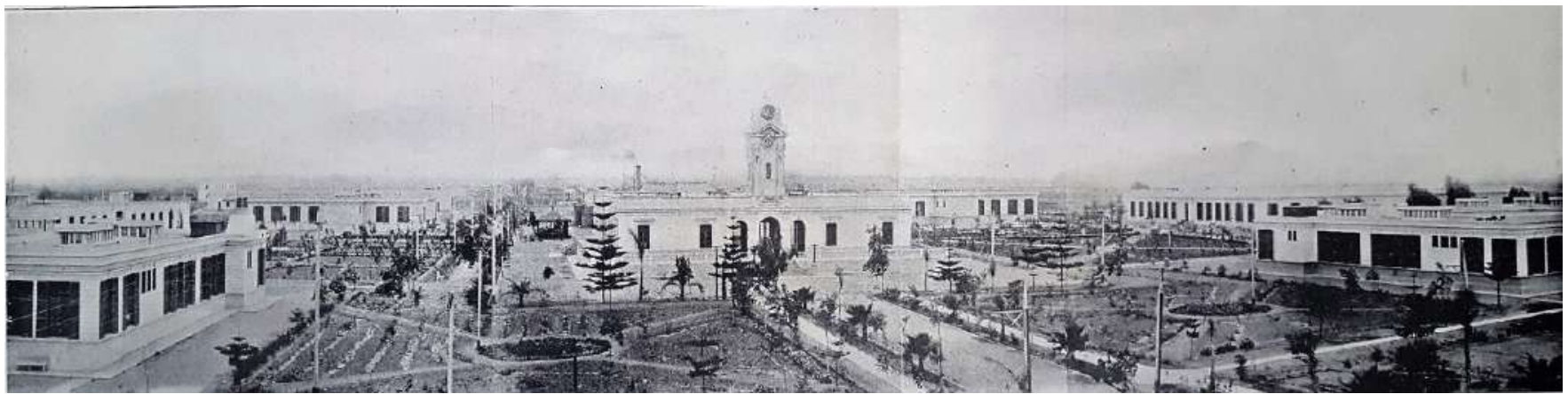

Figura 1. Vista general del Asilo Colonia. Fuente: Asilo Colonia de Magdalena, 1920 (38).

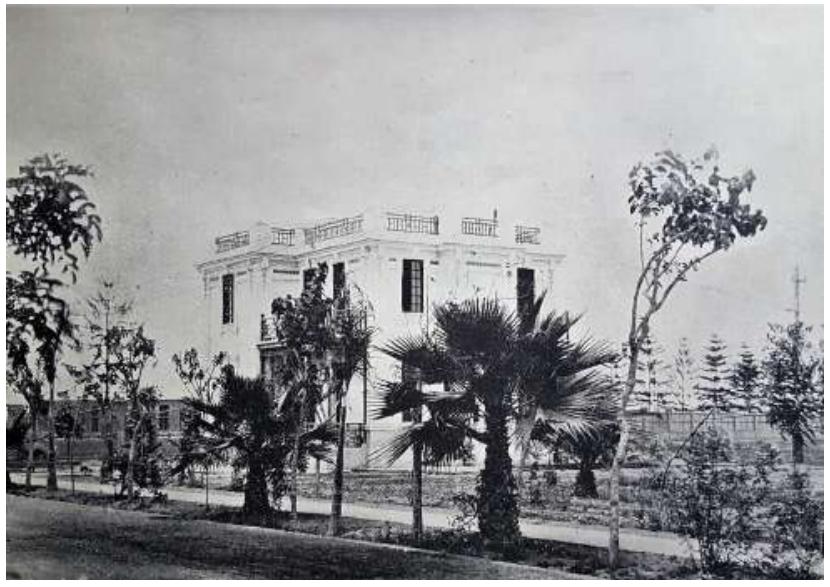

Figura 2. Casa del médico residente.

Fuente: Asilo Colonia de Magdalena, 1920 (38).

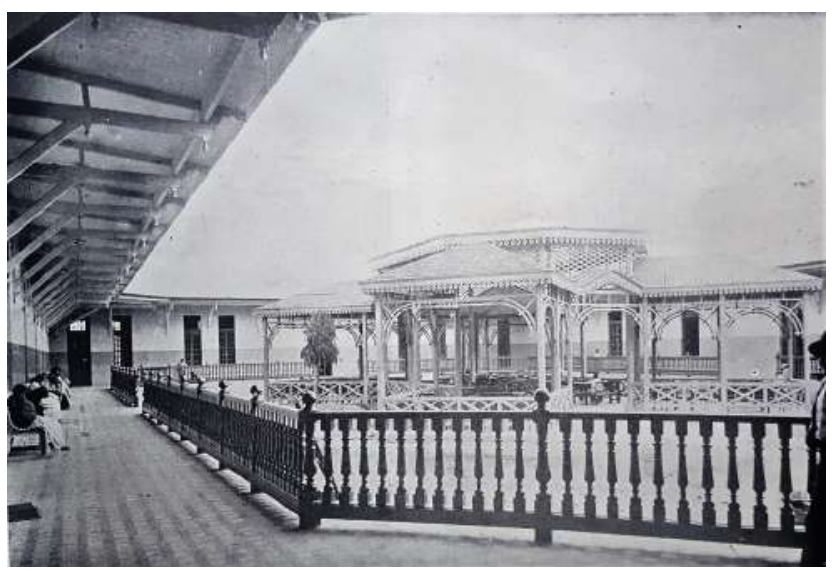

Figura 4. Comedor del pabellón de gratuitas mujeres. Fuente: Asilo Colonia de Magdalena, 1920 (38).

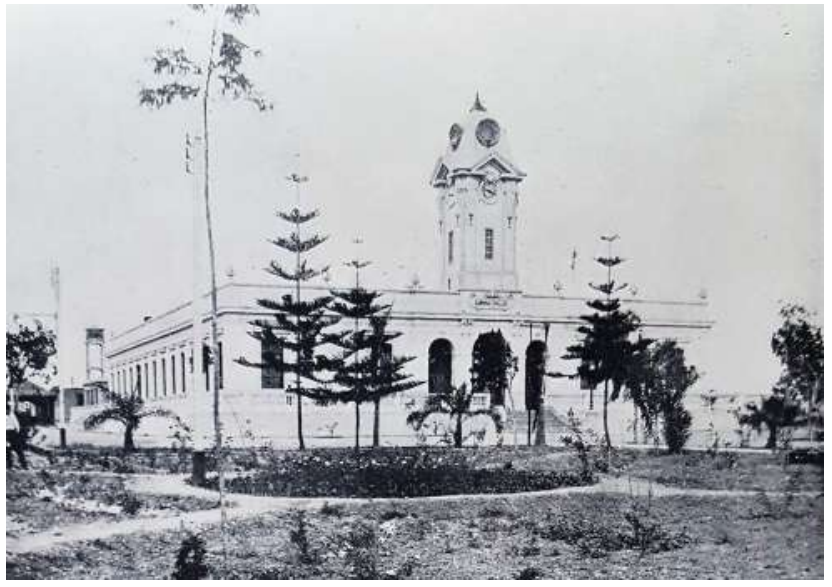

Figura 3. Pabellón de administración.

Fuente: Asilo Colonia de Magdalena, 1920 (38).

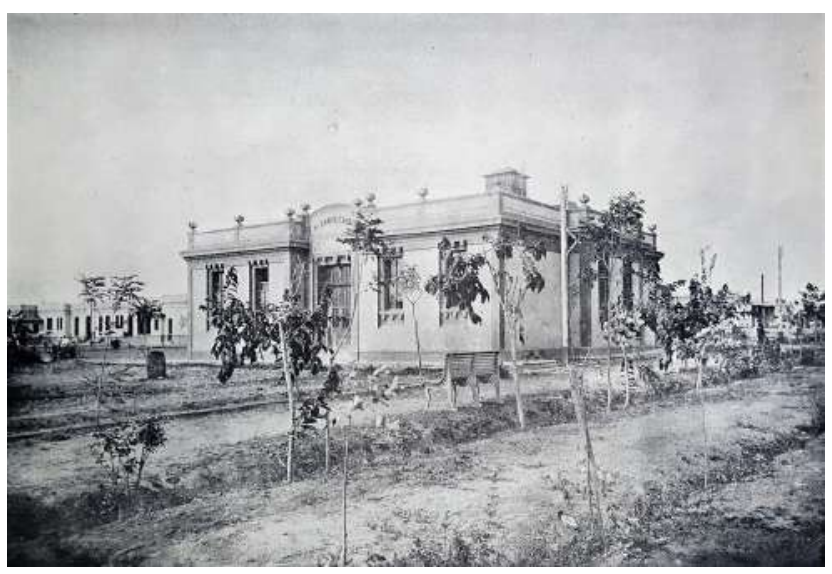

Figura 5. Pabellón de hidroterapia.

Fuente: Asilo Colonia de Magdalena, 1920 (38). 


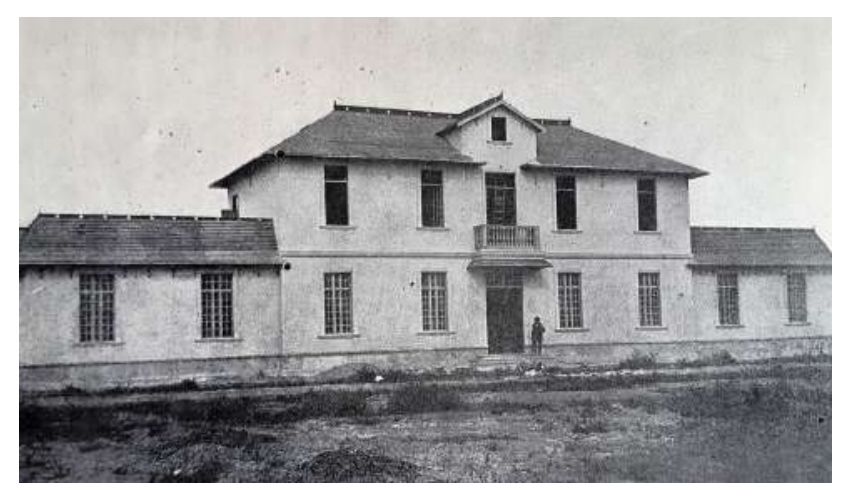

Figura 6. Pabellón de Clinoterapia. Fuente: Memoria de 1920 (39).

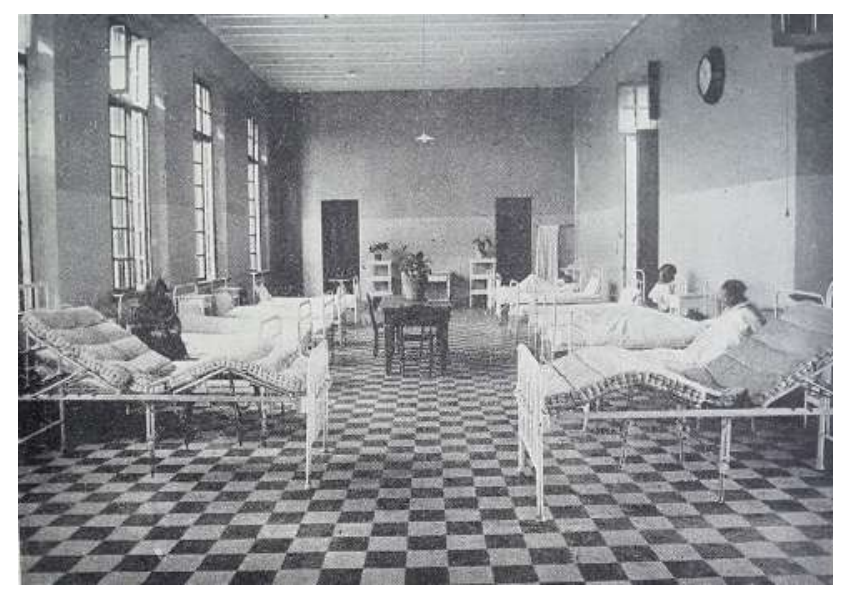

Figura 7. Enfermería y sala de vigilancia del servicio de gratuitas mujeres. Fuente: Asilo Colonia de Magdalena, 1920 (38).

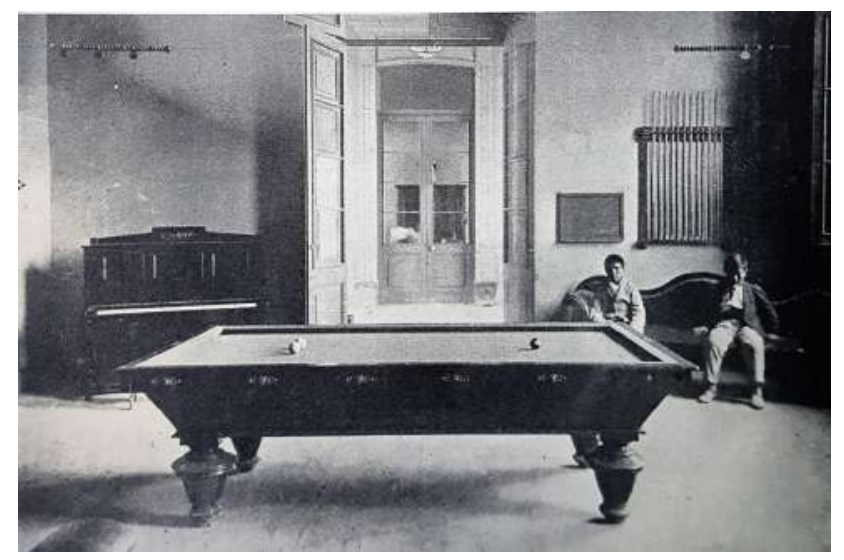

Figura 8. Sala de billar del servicio de gratuitos hombres. Fuente: Asilo Colonia de Magdalena, 1920 (38).

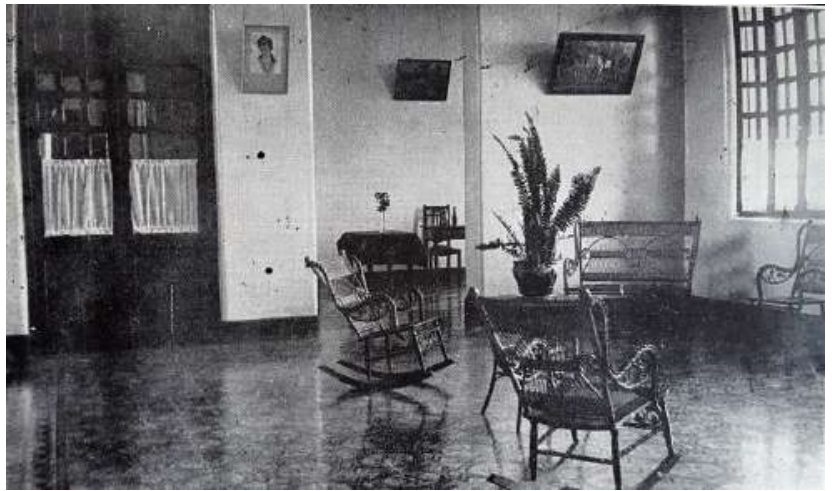

Figura 9. Sala de admisión. Fuente: Memoria de 1920 (39).

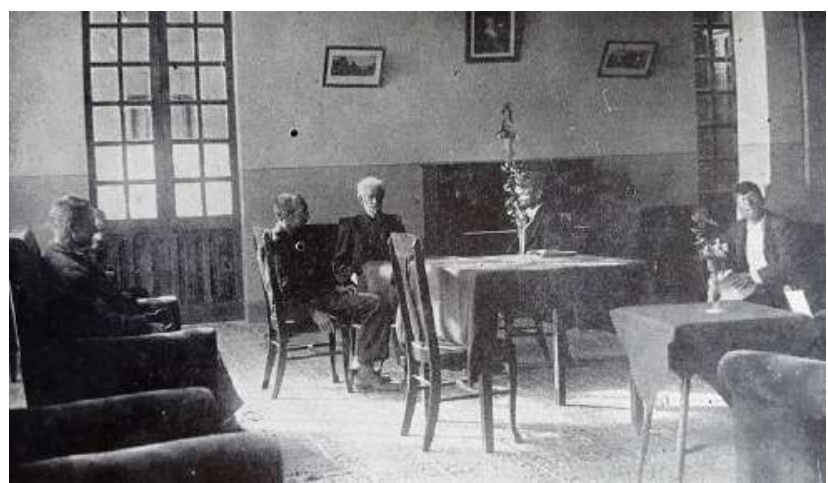

Figura 10. Sala del pensionado. Fuente: Memoria de 1920 (39).

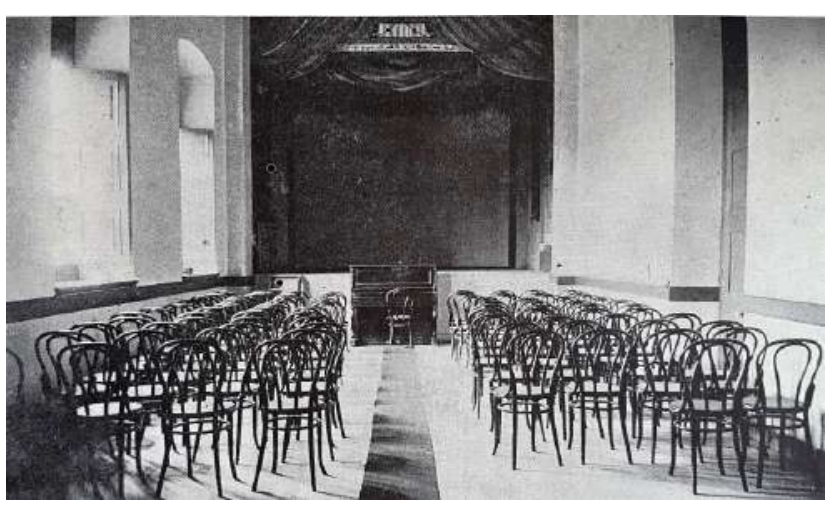

Figura 11. Teatro. Fuente: Memoria de 1920 (39). 


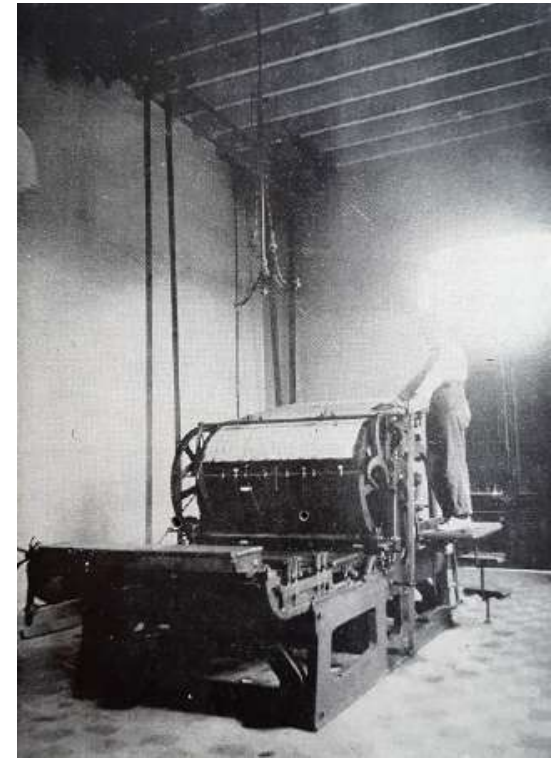

Figura 12. Imprenta. Fuente: Memoria de 1920 (39).

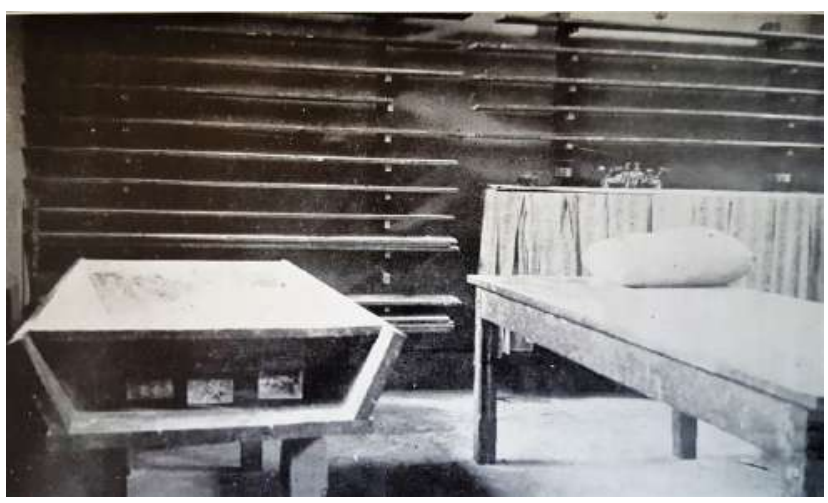

Figura 13. Panadería. Fuente: Memoria de 1920 (39).

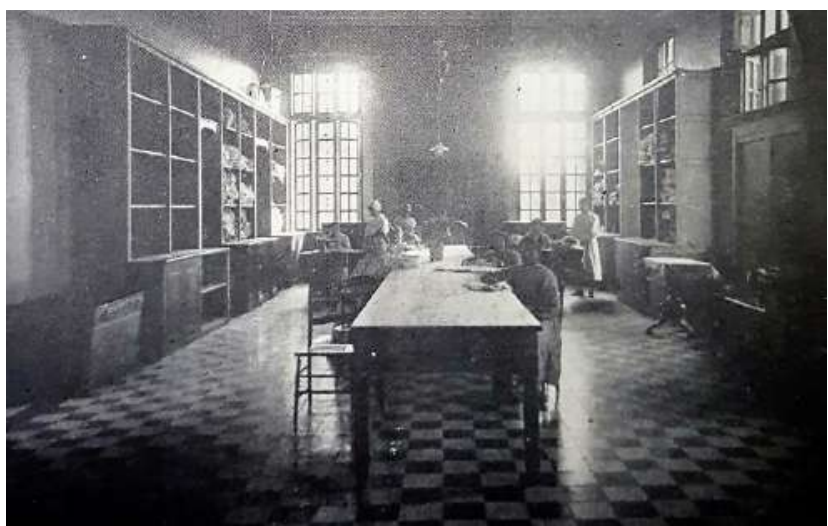

Figura 14. Taller de costura y obras de mano del servicio de gratuitas mujeres. Fuente: Asilo Colonia de Magdalena, 1920 (38).

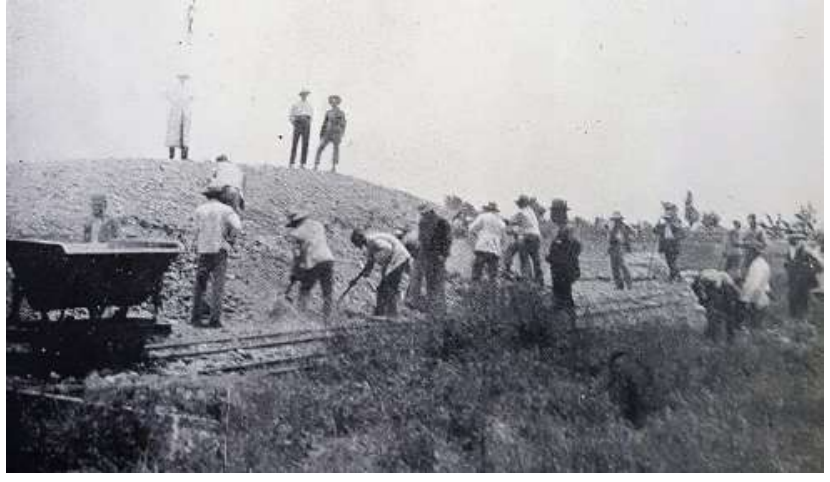

FIGURA 15. Internos trabajando. Fuente: Asilo Colonia de Magdalena, 1920 (38).

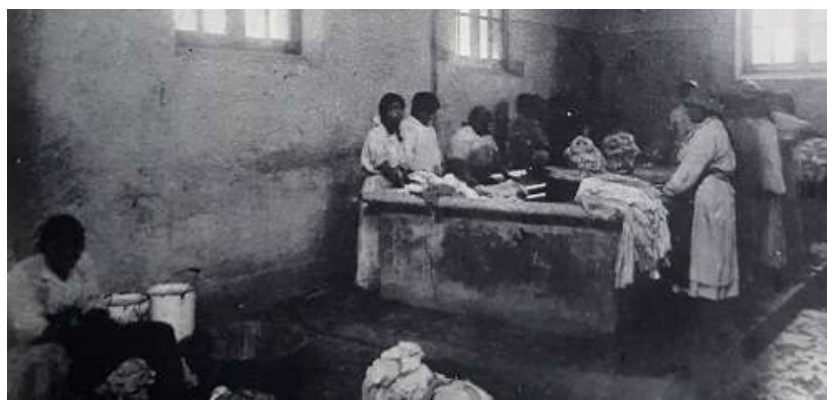

Figura 16. Internas en el lavado. Fuente: Asilo Colonia de Magdalena, 1920 (38).

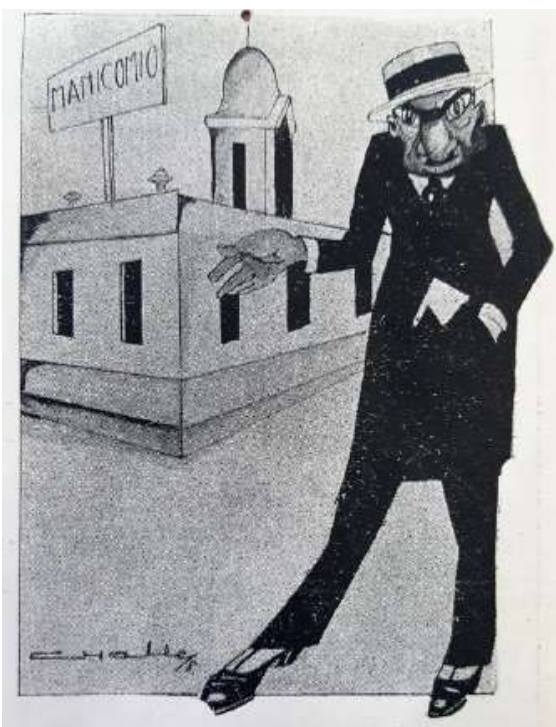

$\mathrm{Y}$ el señor Elguera, preeavido, con muy laudvbles fines, ha hecho entrega del odificio donde muehos patriotas debieran trasladarse.

FIgURA 17. Nota humorística sobre el Sr. Federico Elguera, Inspector al inaugurarse el Asilo

Colonia, en 1918. Fuente: Revista Variedades (40). 